\title{
GÊNERO E TERRITÓRIO EM ESPAÇOS ESCOLARES: REFLEXÕES A PARTIR DA EXPERIÊNCIA DE UMA ESCOLA PÚBLICA DE MACAPÁ-AMAPÁ
}

\author{
GENDER AND TERRITORY IN SCHOOL SPACES: REFLECTIONS FROM THE EXPERIENCE OF A PUBLIC \\ SCHOOL IN MACAPÁ-AMAPÁ
}

\section{Crecencio Pereira Neto ${ }^{1}$ Eliane Cabral da Silva²}

\begin{abstract}
1 Acadêmico do Curso de Geografia Licenciatura da Universidade Federal do Amapá - Campos Marco Zero. E-mail: crecenciopereiran@gmail.com 2 Doutora em Geografia e Docente do Curso de Geografia Licenciatura da Universidade Federal do Amapá - Campos Marco Zero e Coordenadora do Laboratório de Pesquisa e Ensino de Geografia. E-mail: lianecabral@hotmail.com
\end{abstract}

RESUMO: O presente ensaio buscou analisar as composições territoriais nos ambientes comuns de convivência escolar de uma escola pública da rede ensino do Amapá e de como as relações de poder se concebem na dinâmica social a partir das relações de gênero. E de forma complementar apresenta percepções sociais de estudantes de uma turma do $2^{\circ}$ ano do ensino médio sobre as temáticas que envolvem o gênero como forma de subsidiar a reflexão para o estudo. No trabalho foi alinhada considerações da ciência geográfica a partir de análises sobre a categoria território conjuntamente as considerações do estudo de gênero na ciência. Palavras-chave: Território. Espaço. Poder. Gênero.

\begin{abstract}
This essay sought to analyze the territorial compositions in the common environments of school coexistence of a public school in the Amapá teaching network and how power relations are conceived in social dynamics based on gender relations. And in a complementary way, it presents the social perceptions of students in a class of the 2 nd year of high school about the themes that involve gender as a way to subsidize the reflection for the study. In the work, considerations of geographic science were aligned based on analyzes of the territory category together with the considerations of the study of gender in Science.
\end{abstract}

Keywords: Territory. Space. Power. Genre.

Sumário: Introdução - 1 O conceito de gênero e território - 2 Lócus e sujeitos da pesquisa - 3 A percepção de gênero dos/das estudantes - 4 Uma leitura do ponto de visto espacial das relações de gênero entre alunos: o hall da escola e a quadra de esporte como territórios em disputas - 5 A divisão territorial: a margem da quadra, sempre as meninas - Considerações finais - Referências

\section{INTRODUÇÃO}

O presente ensaio emergiu do interesse de pensar e compreender a dinâmica do espaço geográfico escolar, também sobre uma perspectiva de gênero. Nesse sentido, busca-se a partir do estudo de caso na Escola Estadual Marechal Castelo Branco, localizado em Macapá, no estado do Amapá, refletir sobre a relação entre gênero e territórios existentes dentro do ambiente escolar, com o objetivo de demostrar como as relações de gênero socialmente construídas reproduzem no interior do espaço escolar territórios ou microterritórios que fortalecem a desigualdade existente na sociedade e reforçam as relações de poder que subjugam determinado gênero em detrimento ao outro.

O recorte espacial da pesquisa foi o da Escola Estadual Marechal Castelo Branco. Os sujeitos foram os estudantes do ensino médio desta instituição. Em relação a linha teórica-metodológica, adotou-se a Geografia Cultural, alinhada com as conjecturas da geografia de gênero. A geografia cultural é um campo dos estudos geográficos que se arrola na compreensão de perspectivas culturais na transformação da dinâmica espacial. A Geografia de Gênero, por sua vez, compreende a importância social das diferenças sociais de 
gênero e dos corpos na transformação do espaço geográfico.

A pesquisa caracteriza-se como um estudo quali-quantitativo e lançou mão da aplicação de questionários semiestruturado, entrevistas e da observação participante como estratégia para levantamento dos dados empíricos. O questionário foi aplicado a 21 (vinte e um) estudante tendo com o objetivo captar percepções em torno das experiências escolares que relacionam a tônica de gênero. É prudente lembrar que com relação aos nomes dos alunos apresentados nesse trabalho, são todos fictícios em função de manter preservada a identidade dos mesmos.

A Observação Participante foi realizada no período de 12 de setembro a 15 de dezembro de 2016. A opção por essa metodologia foi permite uma interação face a face, com o sujeito ou grupo analisado e assim produzir informações de modo qualitativo sobre suas ações em determinados espaços. Compreendendo-se como caminho metodológico qualitativo para as ciências humanas, abarcando então as perspectivas geográficas, em que se primam pela presença do sujeito no espaço problematizado captando experiências, percepções e o sentido político que pode emanar dos envolvidos no processo investigativo (TURRA, 2012).

Utilizou-se ainda da construção de croquis como estratégia de representação dos territórios ou microterritórios, que foram delimitados a partir da perspectiva de gênero e das reflexões de poder percebida nos espaços pesquisados. A opção pela realização de croquis de localização foi por serem "excelentes instrumentos para a organização de atividades simbólicas. As atividades simbólicas têm por função organizar situações específicas em que o uso do instrumento produz formas fundamentalmente de comportamento"(SARDINHA, 2007, p. 121).

Para discorrer sobre a temática aqui apresentada, o presente ensaio explicita os conceitos de gênero e território, que norteiam as discussões feitas no trabalho. Apresenta os sujeitos da pesquisa e descreve de forma mais detalhada as características do lócus da pesquisa. E discute, a partir do ponto de vista espacial/territorial as relações de gênero entre alunos do ensino médio da Escola Estadual Marechal Castelo Branco.

\section{O CONCEITO DE GÊNERO E TERRITÓRIO}

O conceito de gênero nesse trabalho é entendido como constitutivo de relações sociais baseado nas diferenças percebidas entre os sexos, sendo uma maneia de significar as relações de poder. Para Scott (1989) o uso desse conceito permite abandonar a explicação da natureza como a responsável pela grande diferença existente entre os comportamentos e os lugares ocupados por homens e mulheres na sociedade. Essa diferença historicamente tem privilegiado os homens, na medida em que a sociedade não tem oferecido as mesmas oportunidades de inserção social e exercício de cidadania a homens e mulheres. Mesmo com a grande transformação dos costumes e dos valores que vêm ocorrendo nas últimas décadas, ainda persistem muitas discriminações, por vezes encobertas, relacionadas ao gênero.

O documento Gênero e Diversidade na Escola, publicado pelo Ministério da Educação em 2009, aponta que para as ciências sociais e humanas, o conceito de gênero se refere à construção social do sexo anatômico. Ele foi criado para distinguir a dimensão biológica da dimensão social, baseando-se no raciocínio de que há machos e fêmeas na espécie humana, no entanto, a maneira de ser homem e de ser mulher é realizada pela cultura. Assim, gênero significa que homens e mulheres são produtos da realidade social e não decorrência da anatomia de seus corpos. Por exemplo, o fato de as mulheres, em razão da reprodução, serem tidas como mais próximas da natureza, tem sido apropriado por diferentes culturas como símbolo de sua fragilidade ou de sujeição à ordem natural, que as destinaria sempre à maternidade.

Nesse mesmo documento destaca-se ainda que o modo como homens e mulheres se comporta em sociedade corresponde a um intenso aprendizado sociocultural que nos ensina a agir conforme as prescrições de cada gênero. Há uma expectativa social em relação à maneira como homens e mulheres devem andar, falar, sentar-se, mostrar seu corpo, brincar, dançar, namorar, cuidar do outro e amar. Conforme o gênero, também há modos específicos de trabalhar, gerenciar outras pessoas, ensinar, dirigir o carro, gastar o dinheiro, ingerir bebidas, dentre outras atividades (GÊNERO E DIVERSIDADE NA ESCOLA, 2009, p.40). 
Essas prescrições de agir direcionando cada gênero na sociedade geraram e geram desigualdades profundas no que refere aos papéis sociais exercidos por homens e mulheres. É partir delas que nos diversos períodos históricos e nos diferentes locais, os povos foram classificando as "atividades de trabalho na esfera pública e privada, os atributos pessoais e os encargos destinados a homens e a mulheres no campo da religião, da política, do lazer, do esporte, da educação, dos cuidados com saúde, da sexualidade [...]” (GÊENERO E DIVERSIDADE NA ESCOLA, 2009, p.41).

É dessas concepções que se origina a atual divisão do trabalho na sociedade. E isso é tocar no que vem sendo definido, historicamente como trabalho de mulher, competência de mulher, lugar de mulher e, é claro, também das consequências dessa classificação, que produz ao mesmo tempo, identidades, vantagens e, sobretudo desvantagens conforme afirma Biroli (2018).

O território, por sua vez, tem a ver com o poder, mas não apenas ao tradicional poder político. Ele diz respeito tanto ao poder no sentido mais explícito, de dominação, quanto ao poder no sentido mais implícito ou simbólico, de apropriação. Segundo Haesbaert (2007) o conceito que abarca a produção material e as noções jurídico-político de dominação de determinado espaço, bem como a apropriação em termos imateriais, que se expressa em identidade, simbolismo e subjetividades exprimidas ao exercício de poder. Nesse sentido, tem viés multidimensional, seja no político-jurídico do Estado, na economia e cultural, ou ainda na interação entre eles. Assim, o território pode então nascer de conotações diversas e de combinações dentro de um contexto funcional e simbólico do território.

Para Souza "todo espaço definido e delimitado por e a partir de relações de poder é um território". Ou seja, do "quarteirão aterrorizado por uma gangue de jovens até um bloco constituído pelos países membros da OTAN" (SOUZA, 1995 p.111). Assim, o território não se limita a concepção de estado-nação. O território assim, é entendido pelo exercício de poder por um indivíduo, grupo de pessoas, organizações ou o Estado sobre um determinado recorte espacial, que por sua vez tem sua área delimitada por fronteiras, onde não necessariamente precisam ser visíveis, materiais e bem definidas. Apropriação de determinado espaço e sua influência/poder sobre ele, é compreendido, nas abordagens geográficas trabalhadas, como o expoente que considera o território como instrumento de análise e interpretação da dinâmica socioespacial.

A opção pelo conceito de território para proceder a leitura do espaço escolar deve-se ao fato, de ser esse o conceito da geografia, que melhor permite compreender a simbiose entre relações de poder e produção do espaço. A identificação da constituição territorial no interior da escola foi compreendida a partir das relações de poder e os conflitos inerentes que foram evidenciados no dia a dia nos espaços coletivos, conflitos dos quais tinha como frente usos distintos dos espaços entre os alunos tomando como diferencial as percepções sobre gênero.

\section{LÓCUS E SUJEITOS DA PESQUISA}

O recorte espacial da pesquisa foi o da Escola Estadual Marechal Castelo Branco (figura 1), sobretudo, os locais de uso coletivo, como a sala de aula do $2^{\circ}$ ano do ensino médio vespertino, a quadra de esportes e os halls e corredores de acesso do colégio. A Escola é considerada uma das mais tradicionais do Amapá. Localizada no Bairro do Trem, fica na região central da cidade Macapá-Amapá. Em suas adjacências estão os bairros Beirol, Muca, Novo Buritizal e Santa Inês que possuem uma alta ocupação demográfica e concentram moradores com condições socioeconômicas que variam de pobres a renda média. A escola é muito procurada pelas famílias moradoras do bairro mencionados, visto ser uma das principais que oferece os três anos do ensino médio na região. 
Figura 1 - Mapa de localização da Escola Estadual Marechal Castelo Branco

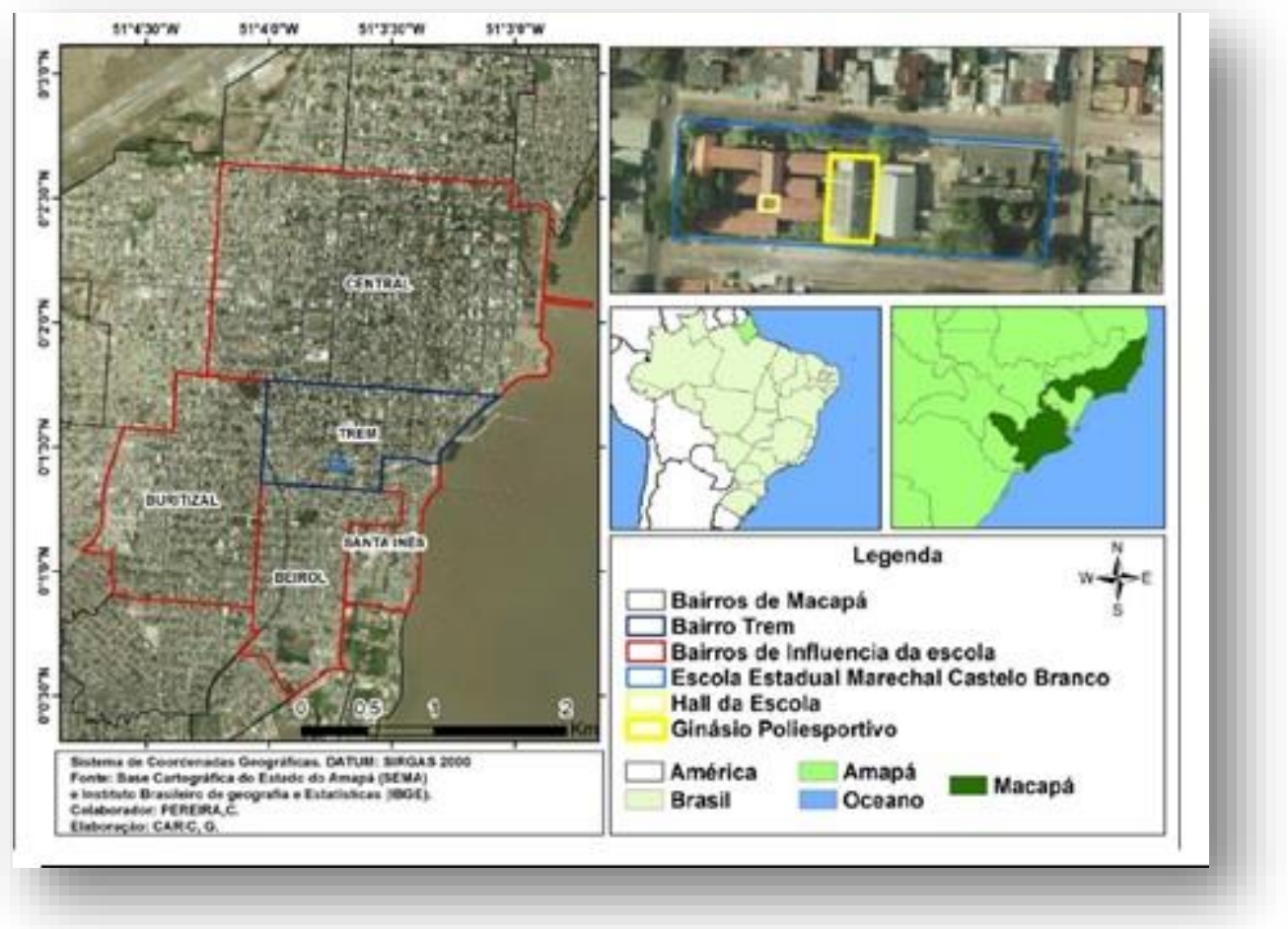

Fonte: Adaptado Base Cartográfica do Estado do Amapá e Instituto Brasileiro Geografia e Estatística (IBGE).

Em seu histórico, a violência se apresenta como marca resultante de episódios como a tentativa de homicídio com arma de fogo a um aluno dentro da sala de aula em 2013. Além disso, atividades ilícitas desenvolvidas nas imediações da instituição fortalecem a percepção de violência, como é o caso do tráfico de drogas. Fatores que contribuíram para a inserção da escola no plano de rondas da guarnição de Policiamento Escolar da Polícia Militar do Estado do Amapá (PMAP).

Os sujeitos da pesquisa foram as estudantes e os estudantes de turmas do Ensino médio, turno vespertino. Esses jovens apresentavam idade entre 15 e 17 anos e, segundo informações dos próprios docentes, são filhos de trabalhadores e trabalhadores de renda baixa e média. Ao todo cinquenta (50) estudantes participaram das etapas da pesquisa, 21 (vinte um) deles em específico, responderam o questionário que foi aplicada, os outros 29, foram envolvidos a partir observação participante e da realização de entrevistas.

\section{A PERCEPÇÃO DE GÊNERO DOS/DAS ESTUDANTES}

Seguindo na problematização dentro da sala escolhida como amostra, foi realizada aplicação de questionários para 21 (vinte e um) alunos que estavam presentes, os quais puderam de forma anônima expor seus entendimentos sobre algumas proposições destacadas. Foram redigidas indagações com objetivo de subsidiar a reflexão acerca das noções dos alunos sobre pontos macro da discussão que envolve o gênero como pauta.

Entre as questões respondidas pelos estudantes, apresenta-se nesse texto três que foram consideradas mais relevantes para reflexão sobre as percepções de gênero com tal público. A primeira pergunta destacada aos alunos diz respeito ao tocante à ações que denotam discriminação de gênero sofrido ou presenciado no ambiente escolar. No Gráfico 1 é evidenciado a resposta das alunas e alunos. 
Gráfico 1 - Discriminação relacionado ao gênero no espaço escolar

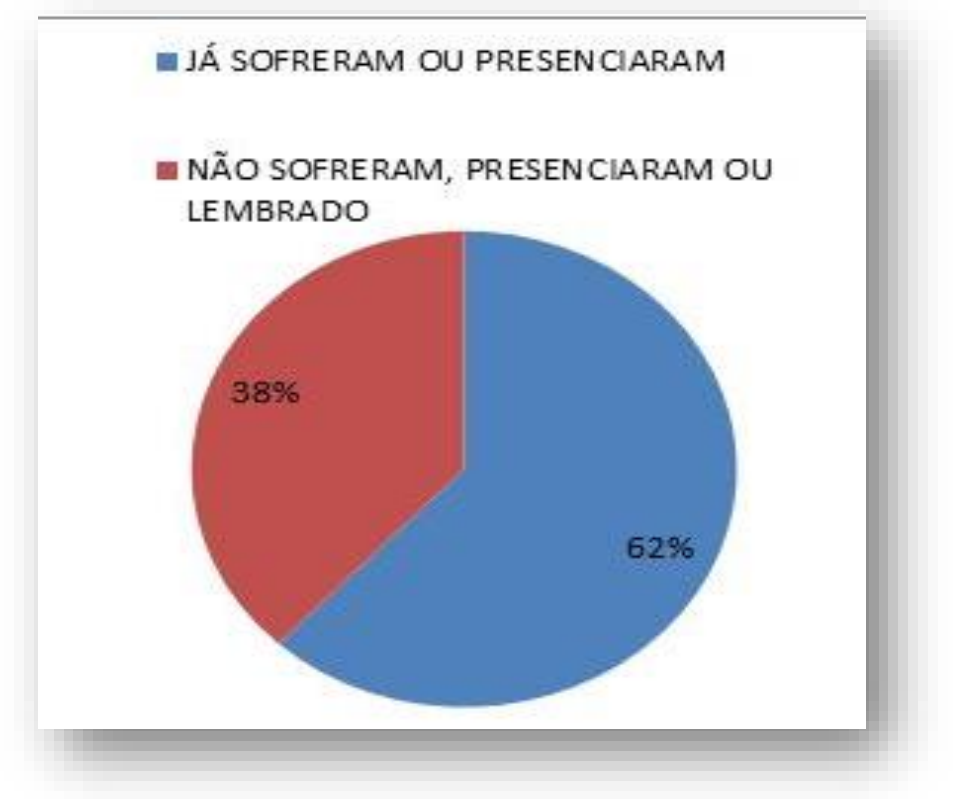

Fonte: Trabalho de Campo, 2016.

A análise representa em números inteiros que 13 (treze) alunos já sofreram ou presenciaram alguma ação discriminatória relacionando o gênero no ambiente escolar, por outro lado oitos (8) alunos disseram que não sofreram, não lembraram de ter sofrido ou presenciado algo relacionado.

O considerável percentual de 38\% que representa os oito (8) estudantes que tiveram a ausência de atos discriminatórios em suas percepções podem levar a pontos distintos a se refletir: ausência como fator positivo que pode decorrer de um espaço escolar mais democrático e menos reprodutor de tensões que relacionam o gênero como expoente, ou em uma perspectiva negativa que representaria um espaço em que as ações problemáticas entre gêneros acabam tomando pouca importância, se naturalizando no cotidiano da vida escolar e nas relações sociais nela presente.

No entanto, são ponderações que não podem anular e negar a necessidade de se pensar sobre a constatação favorável de $62 \%$ dos alunos, que fundamentam a importância das abordagens em trabalhos como este. Ou seja, a maioria dos estudantes ao responderem positivamente à pergunta evidenciam a presença da problemática no contexto escolar, mas para além disto, demostram que existe no conjunto de alunos certa consciência ou percepção de que as relações de gêneros podem ser desiguais ou produzir situações negativas.

A segunda indagação destacada das considerações dos alunos e alunas foi sobre a ocupação dos espaços, mas especificamente na relação de trabalho/atividade e sua divisão entre o feminino e masculino. O gráfico 2 representa o que foi respondido pelos estudantes por meio da aplicação do questionário. 
Gráfico 2 - Há, na sua concepção a existência de trabalhos/atividades mais adequados para homens e outros mais adequados para mulheres?

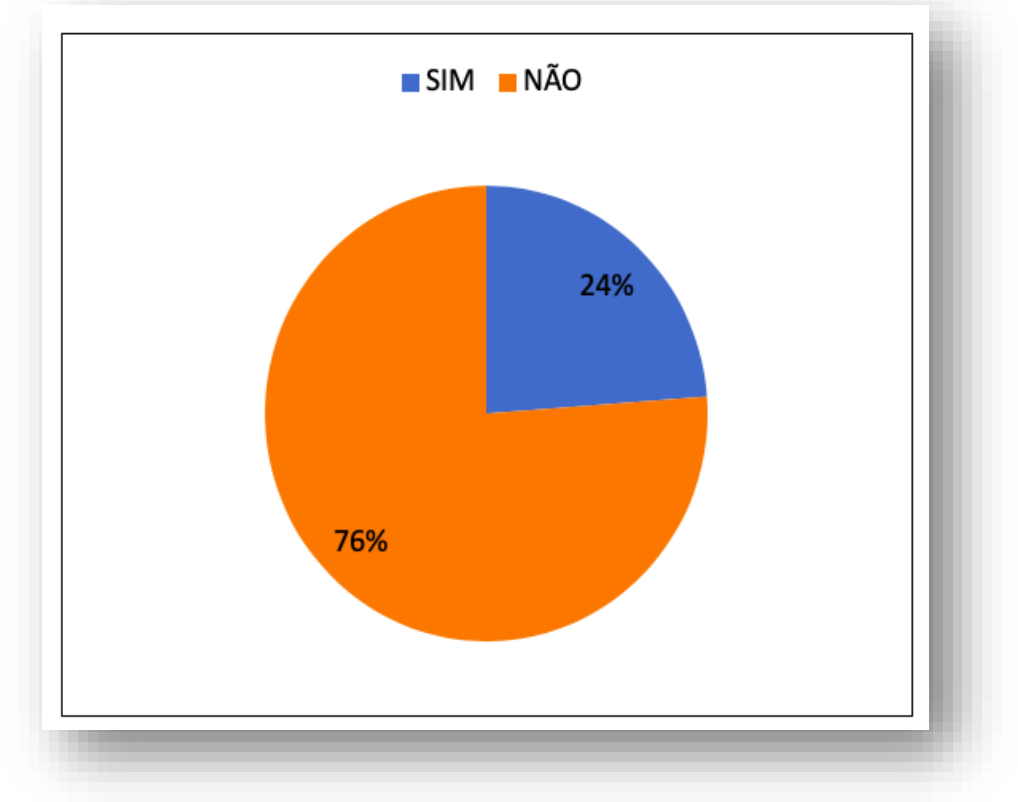

Fonte: Trabalho de Campo, 2018.

A construção da pergunta foi feita com o propósito de evidenciar o discurso determinista sobre espaços, no intuito de auxiliar no discernimento das percepções sociais dos alunos sobre as delimitações de atividades. A maioria respondeu não ao questionado, mais precisamente $76 \%$ dos entrevistados, demonstrando uma visão progressista sobre o ponto central. Contudo, $24 \%$ dos estudantes e das estudantes disseram sim, visões que pesam ao levarmos em consideração construções simbólicas na sociedade em torno de atividades e áreas de atuação, as quais historicamente são consideradas como vinculadas a questões biológicas de diferenciação entre gêneros, de ordem de força física por parte do masculino e a delicadeza remetida ao sentimentalismo do feminino.

O que nos remete ao discutido por Biroli (2018) quando fala que é a divisão do trabalho sobre a perspectiva patriarcal, que vem definido, historicamente o que é trabalho de mulher, competência de mulher, lugar de mulher, e é claro, também das consequências dessa classificação, que produz ao mesmo tempo, identidades, vantagens e, sobretudo desvantagens.

Além das proposições expostas nos gráficos, tivemos nos questionários pergunta sobre como temática de gênero aparece no âmbito institucional escolar. Como quando indagado sobre ações escolares, projetos, oficinas ou similares que abordassem a discussão de gênero e afins no ambiente de ensino. As respostas em grande maioria referenciavam o não e outras respostas citaram a comemoração do dia da mulher como evento que abarcava em suas perspectivas o tema, tal ponderação foi confirmada junto ao corpo pedagógico da escola.

Destaca-se que o período de observação junto da turma se deu durante as aulas de geografia, entretanto, os apreços ocorrem em torno das relações sociais estabelecidas entre os alunos, nos eximindo de análises sobre o conteúdo dado em aula. Ainda foi propositado estadia em sala em diferentes disciplinas durante o período de estudo, porém houve resistência da coordenação pedagógica tendo como justificativas a procura da escola por outros acadêmicos de diferentes cursos para realização de estágios e pesquisas. 


\section{UMA LEITURA DO PONTO DE VISTO ESPACIAL DAS RELAÇÕES DE GÊ- NERO ENTRE ALUNOS: O HALL DA ESCOLA E A QUADRA DE ESPORTE COMO TERRITÓRIOS EM DISPUTAS}

Como já apontado na metodologia às observações realizadas no espaço da escola Estadual Marechal Castelo Branco levaram a identificação de locais que chamaram atenção pela aglomeração de estudantes. Contudo, esses pontos chamam atenção em especial pela sua forma de ocupação, espaços que problematizam o relacionamento entre gêneros e as relações de poder como modelador territorial das ocupações. Nesse ensaio, esses locais serão destacados por representações gráficas (Figuras 2 e 6) e croquis (Figuras 3, 4, 5 e 7). A partir da constituição das representações é possível refletir em torno da forma de ocupação percebida nestes espaços, trabalhando com as percepções das relações sociais que relacionam o gênero como expoente no ambiente escolar.

$\mathrm{Na}$ Figura 2 é apresentado graficamente o hall da escada de acesso ao $2^{\circ}$ andar da escola, local que durante o processo investigativo foi percebido a presença de relações sociais que se entrelaçam com a questão de gênero. Neste sentido, a abordagem deste local é necessária para entender a existência de impactos na configuração espacial do hall a partir destas relações interpessoais. Ou seja, o hall representa um espaço de azilação dentro da instituição de ensino.

$\mathrm{Na}$ figura os pontos em destaques são depreendidos a partir das concentrações de estudantes no espaço que se intensifica principalmente no horário do intervalo recreativo, momento em que as ações e relações dos sujeitos ali presentes são exercidas com maior espontaneidade.

As marcações 1 e 3 se localizam próximo do acesso a escada, consideradas como pontos que sobressaíram na representação tendo em vista o aglomerado de discentes do gênero masculino. Já as marcações 2 e 4 são percebidas pela concentração esporádica de estudantes tanto do gênero masculino quanto do feminino, sendo realçados para ajudar em uma melhor compreensão espacial do ball do $2^{\circ}$ andar da escola.

Figura 2 - Pontos de concentração no hall da escada do $2^{\circ}$ pavimento da escola

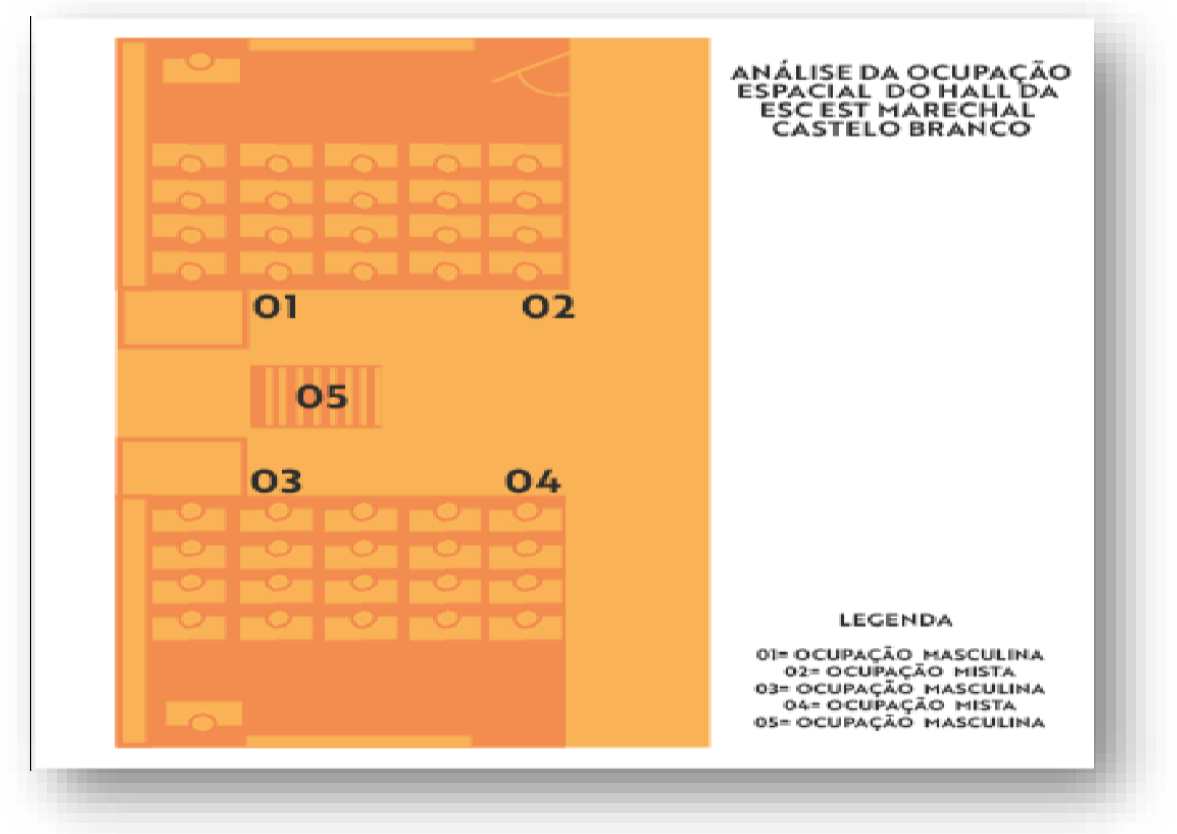

Autor: CUNHA, Matheus, 2018.

Ao analisar, a partir da observação direta, os pontos 1 e 3, foram subtraídas premissas em torno das dinâmicas de ocupação. Premissas estas ratificadas a partir das entrevistas realizadas com discentes, quando 
se percebeu as noções sobre divisão e usos dos pontos citados. Por meio das observações foi possível notar, devido os uniformes escolares usados, que a maioria dos alunos que se concentravam nos espaços do ponto 1 e 3 eram alunos do $3^{\circ}$ ano do ensino médio, uma vez que é tradicional o uso da descrição, Formandos, acompanhado do ano de conclusão.

A fim de fazer uma melhor leitura da dinâmica espacial, foram construídos croquis com os pontos principais de concentração dos alunos durante o intervalo recreativo. Nas Figuras 3, 4 e 5 tem-se os primeiros croquis do hall do segundo pavimento da escola.

Figura 3: Croqui do hall do $2^{\circ}$ pavimento da Escola E.M. Castelo Branco

Autor: SILVA, Valdelicer Fonseca, 2018.

Figura 4: Croqui do ball da escada do $2^{\circ}$ pavimento da escola

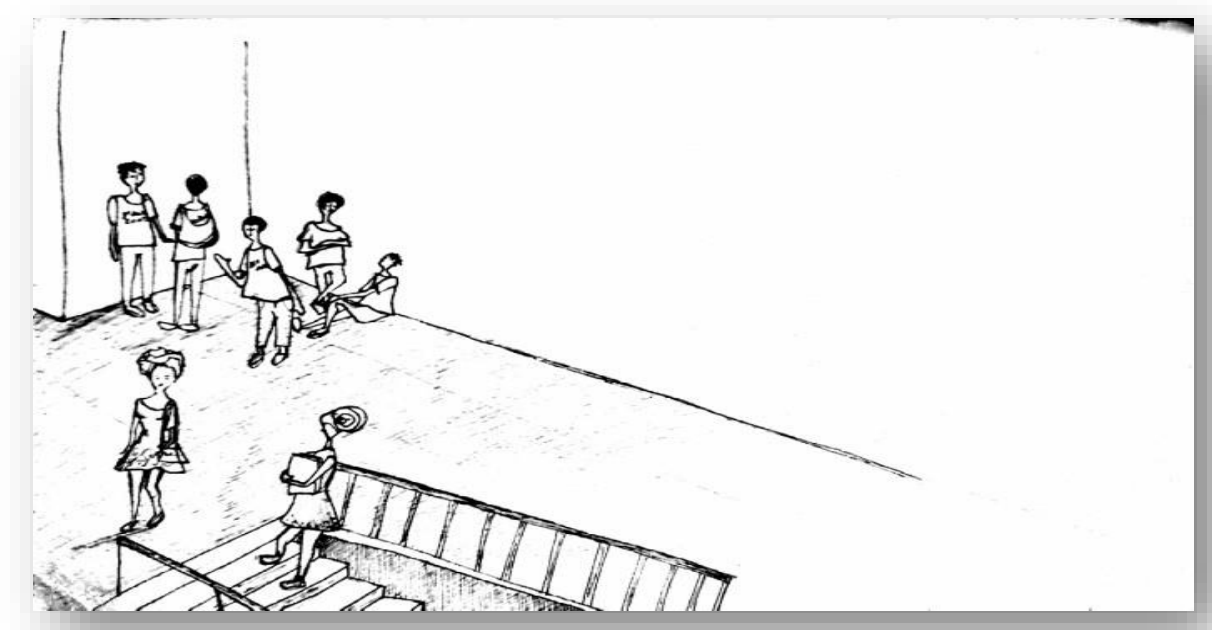

Autor: SILVA, Valdelicer Fonseca, 2019. 
Figura 5: Ponto de concentração de meninos

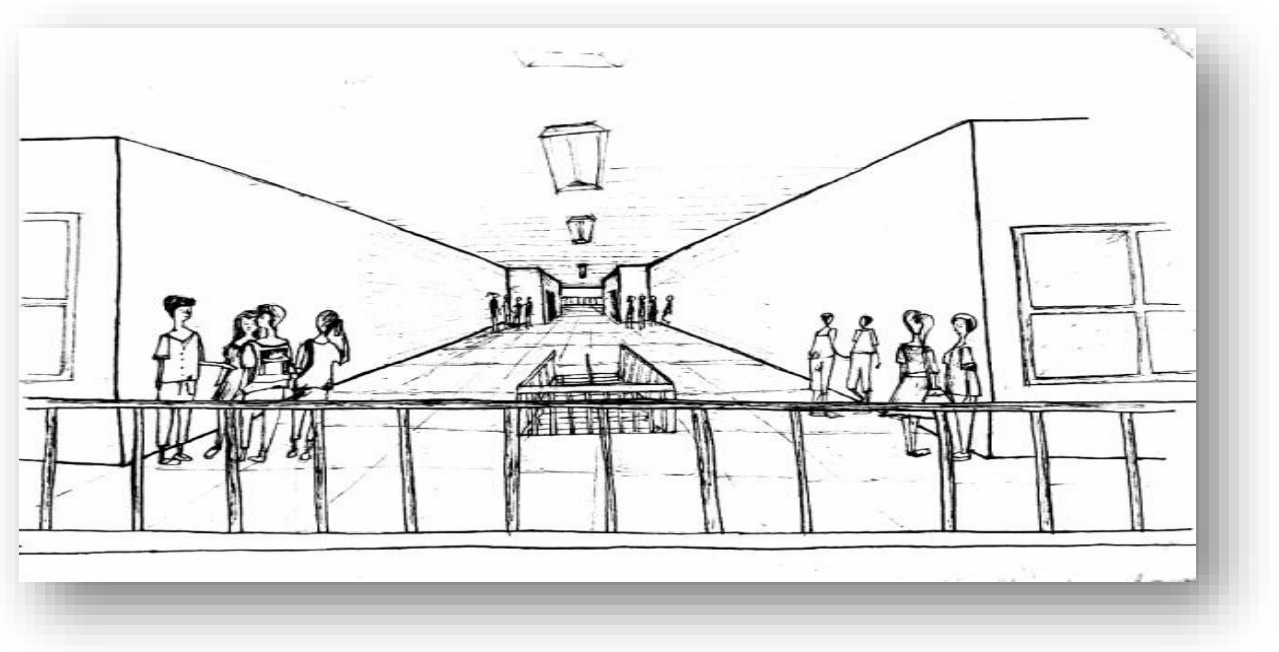

Autor: SILVA, Valdelicer Fonseca, 2019.

$\mathrm{Na}$ Figura 3, a percepção de primeiro momento remete em uma aglomeração aleatória dos indivíduos, entretanto, observando a vivência na escola, foi possível perceber o despertar para um dinamismo de expressões que ali se organizava espacialmente. É possível notar, também, que a grande maioria, independentemente do nível escolar, era de alunos do gênero masculino. Situações que em parte aparecem melhor representadas nas Figuras 4 e 5.

Essas constatações, inicialmente, originaram perguntas sobre o porquê do aglomerado constante, que se juntou a outras indagações - o porquê da maior presença de meninos do que meninas naquele espaço? Qual era a visão daqueles que ocupavam e daqueles que se encontravam no exterior dos pontos? Havia algum impacto na configuração espacial que envolvesse a relações de gênero a partir das ocupações dos pontos?

As entrevistas com os discentes ajudaram a entender um pouco mais sobre as inquietações observadas. Entre os estudantes que se posicionavam em torno dos pontos de estudo as respostas se mostraram lineares, apontando para o entendimento comum sobre as presenças, bem como sobre as ações exercidas nos pontos. Algumas respostas das/dos estudantes sobre as ocupações, buscando desta forma entender mais sobre a dinâmica territorial presente nestes pontos.

O primeiro sujeito abordado foi o aluno João e a ele foi perguntado o porquê da maioria dos alunos ocupantes do ponto 1 e 3 serem do $3^{\circ}$ anos: não sei o porquê, quando entrei sempre via eles (alunos do $3^{\circ}$ ano) lá. Continuando com as refutações foi indagado se existia para ele algum significado/interesse presente na ocupação daqueles pontos e sobre a presença maior dos meninos e a resposta foi: Não sei. Mas os azilões ficam ali se achando, bagunçando". A aluna Patrícia, também, foi entrevistada e respondeu a esta questão afirmando que "Não sei. Quando passamos por lá ficam olhando e as vezes mexem; eles ficam lá se achando. Pensam que são bonitos. Perguntada se aquelas ações de certo modo a incomodava, a aluna balançou a cabeça positivamente.

Em sequência José, aluno do $2^{\circ}$ ano, em resposta as reflexões sobre a maior presença de meninos, sendo eles em maioria do $3^{\circ}$ ano do ensino médio, a resposta foi a seguinte: nem percebi, mas acho que muda com o tempo, com a saída dos formandos. E sobre o que representa a ocupação daquele espaço próximo ao acesso a escada o aluno respondeu: corredor da bagunça, a estudante Maria respondeu a essa mesma questão afirmando que: desde que entrei na escola o terceirão fica ali enchendo o saco, ficam ali mexendo e bagunçando.

$\mathrm{Na}$ entrevista, o aluno Pedro ajuíza sobre a presença no espaço afirmando: sei lá por que sempre estamos aí, mas ficamos aí. Quando perguntado detalhadamente sobre a existência ou não de interesses 
em torno das presenças nos pontos, em especial sobre a noção de bagunça e azilação citadas pelos outros entrevistados, Pedro expressa: fico só lá com a galera, pelo menos no meu caso, já outros azilando e brincando. Em destaque nas entrevistas o termo azilação que já havia sido citado pelo aluno João é concebido dentro do contexto das gírias do grupo estudado como ato de paquera.

Outros três estudantes, sendo duas mulheres, que frequentam de forma esporádica os pontos de aglomeração citados, fizeram as seguintes considerações: ponto para paquera? Não sei se é para eles, isso não posso afirmar e nem negar, mas no meu caso eu não; são meus amigos, prefiro os amigos homem, disse Julia. Já a aluna Ana ao ser questionada sobre o que achava da maioria dos indivíduos que frequentavam os pontos serem homem, seus interesses e o impacto das presenças, a aluna respondeu: pior, nem reparei. Fico aqui mais com a Julia e com os meninos conhecidos, mas eles ficam lá bagunçando.

Por fim, o aluno Diego, que sempre estava no intervalo das aulas nos pontos 1 e 3 , relatou que: é o setor da galera do terceirão. Indagando o porquê é o setor do terceirão, disse: nem sei, sempre foi assim. Inquirido, também, se o espaço se tratava de um lugar de azilação, como dito pelo aluno João, e ele sorri e confirma: É, os galãs ficam azilando direto.

Assim, considerando o que foi observado e no coletado enquanto informação, o entendimento da presença de lógicas atribuídas nos pontos para além das simples presenças de jovens garotos do último ano do ensino médio. São considerações sobre a ocorrência de ações que geram impactos no espaço escolar a partir das relações sociais instituídas, as quais qualificam e reforçam a necessidade de reflexão sobre elas.

Em um primeiro questionamento temos a noção de uso dos espaços em grande parte a garotos formandos, percepção captada pelas observações e ponderada nas entrevistas, as quais concebem que os alunos ao ingressarem na escola percebiam que tais espaços já eram ocupados neste formato, então digerindo como algo cultural na organização socioespacial, resultante de uma divisão comum em espaços de sociabilidade que são as escolas.

Todavia, em reflexão sobre as informações compiladas sugerisse que as ocupações dos pontos citados estariam conjecturadas para além da noção construída culturalmente de sempre estarem nos espaços, mas sim também alicerçado nas relações de poder, especificamente na relação entre os veteranos, restante dos estudantes e especialmente com as estudantes.

Fator maior que nos chama atenção nas falas dos entrevistados, precisamente nos momentos em que usam os termos "azilação" e "mexer" para se referirem as ideias de que alguns alunos usam o espaço em parte na intuitiva da "paquera" ou para tentarem chamar atenção das alunas que ali passam. Tal narração nos faz refletir sobre as ações dos meninos que podem ser traduzidas como assédio, percepções já citadas anteriormente, o que propiciaria deste modo o incomodo para as estudantes que passassem por lá.

Considerações que fazem parte do entendimento sobre a pouca presença das alunas nos espaços, delimitada em partes pelas ações de incomodo exercidas pelos garotos, que são destacadas pelas observações e por maior parte dos entrevistados, mas renegados pelos entrevistados ocupantes dos espaços, como na fala do aluno Pedro.

\section{A DIVISÃo TERRITORIAL: A MARGEM DA QUADRA, SEMPRE AS ME- NINAS}

Outro ambiente de convivência da escola que observamos relações territoriais a partir da perspectiva gênero foi o da quadra poliesportiva, representada nas figuras 6 e 7 .

Assim como no primeiro recorte estudado, usamos dos croquis (Figura 7) como ferramenta de representação da dinâmica organizacional dos pontos em destaque. Consistindo desta forma em representações que vão dividir a problemática entre o espaço central das atividades dentro da quadra, que na figura 8 se apresenta pela cor azul, e o que denominamos de parte periférica da quadra, que é representada pela cor laranja. 
Figura 6 - Quadra Poliesportiva da Escola

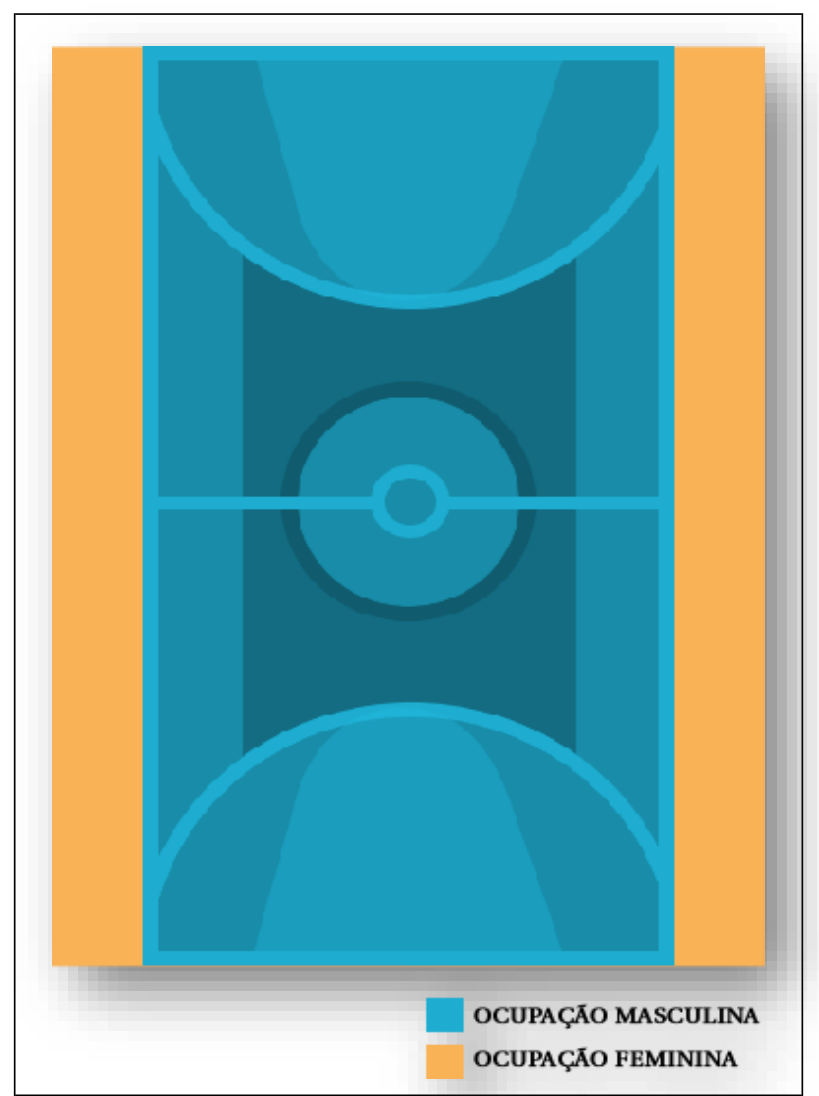

Autor: CUNHA, Matheus, 2018.

A intuitiva de trabalhar com a quadra veio estimulado pela significativa presença de alunos durante os intervalos recreativos, onde foi possível vivenciar a partir da observação direta a organização espacial e as relações sociais que se arrolam perante o exercício de poder. Logo tal questão foi tratada como um possível expoente para o estudo levando em questionamentos a divisão espacial dos pontos entre os gêneros ocupantes.

$\mathrm{Na}$ figura 7 temos a representação através de croqui do ponto analisado, destacamos que a ela não será traçada uma distinção do perfil dos alunos quanto ao nível de escolaridade, tendo em vista a circulação de diversos sujeitos, o que não possibilitou uma uniformidade para exame. Contudo, em termos gerais foi possível detectar a presença de alunos dos três níveis do ensino médio regular. 
Figura 7 - Croqui da ocupação da quadra poliesportiva da Escola E. M. Castelo Branco

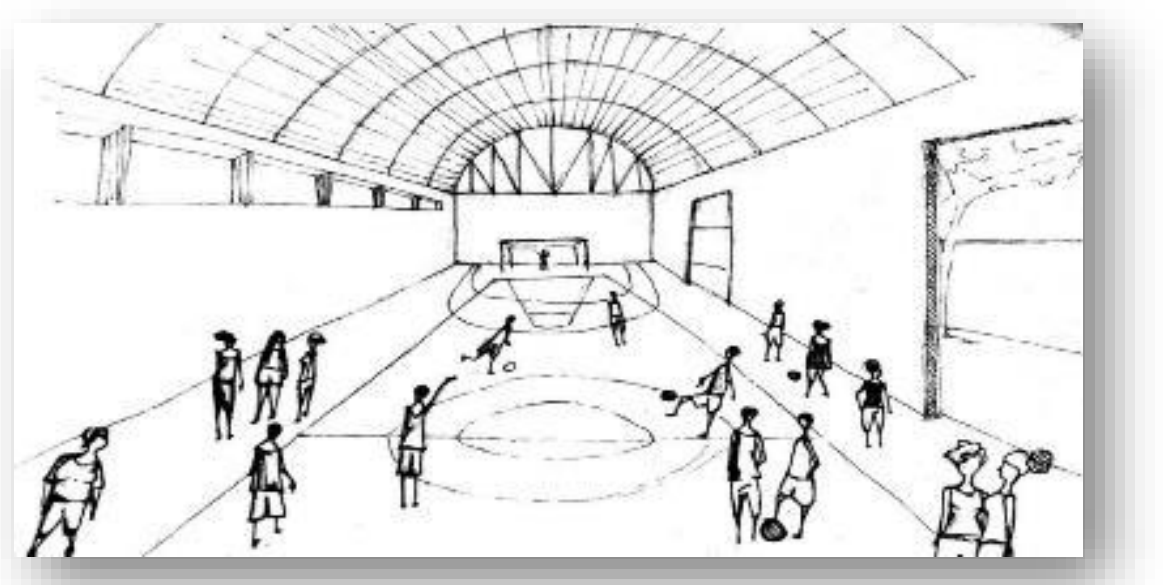

Autor: SILVA, Valdelicer Fonseca, 2018.

Sobre o uso dos espaços da quadra foram captadas em entrevistas dizeres os quais remetem a organização territorial e ao conflito constante entre gêneros. Ao perguntarmos a duas alunas que fazem uso da quadra para a prática recreativa, sobre o porquê de estarem quase sempre na lateral da quadra e não no meio, as respostas apontam para o conflito: "Os meninos se acham os donos da quadra; quando eles chegam depois da gente e querem usar toda a quadra, começam a chutar a bola de lado para o outro, aí com medo que pegue na gente saímos", reponde a aluna Aline.

Por sua vez a aluna Joana disse: "não deixam usarmos porque ficam jogando futebol". As respostas demonstram que as meninas querem usar os espaços centrais da quadra também, mas que tem a opressão por parte dos alunos do gênero masculino na intuitiva do uso da quadra, ainda mais por representar momentos recreativos onde não há uma orientação de professores e as ações de uso do espaço acabam ocorrendo sem regulação por parte de um sujeito diferente aos estudantes.

Dois outros alunos entrevistados, que fazem o uso da quadra no intervalo, os quais chamaremos de Alex e Carlos, quando perguntados sobre o porquê de a geografia da quadra apresentar as alunas nas laterais enquanto os alunos usam a maior parte dela, dissera:" por que para jogar dois times precisamos das duas áreas" (Alex); "acho porque somos mais que elas e por isso usamos mais a quadra" (Carlos).

Entende-se como a área citada pelo aluno Alex a metade da marcação completa da modalidade futsal, que na figura 8 é representada com azul. Já Carlos em sua ponderação coloca que na quadra durante o intervalo recreativo há mais meninos do que meninas e por isso da presença maior dos alunos no espaço central. Porém, durante as observações foi constatado que mesmo em momentos onde as alunas eram o maior número presente em comparação aos alunos, estes continuavam exercendo seu domínio territorial e assim impondo seu desejo no uso da quadra, independentemente da situação numérica de gênero apontado por Carlos.

Durante o processo de pesquisa foi perceptivo que os meninos exerciam essa maior influência sobre o uso do espaço, mesmo em momentos onde havia mais alunas do que alunos na quadra, muitas vezes pareceu que a validação das atividades deles somente seria efetivada quando suas demandas sobre espaço fossem atendidas, inclusive por meio da delimitação das práticas das alunas enquanto não recuassem para os pontos periféricos. Concepção reafirmada pela fala da aluna Aline quando expõem que os meninos quando querem usar a maior parte da quadra e desta maneira realocando as meninas para a parte laterais, começam a chutar a bola de um lado para o outro na intuitiva de impor medo do choque das bolas nas alunas, fazendo desta forma realocação do grupo de meninas por meio da opressão física.

A dominação masculina sobre as áreas da prática esportiva em termos gerais se apresenta como cultural nas escolas, incluindo a realidade que vivenciei como estudante secundarista. Constrói-se uma 
suposta noção e a associação da prática esportiva ao gênero masculino, que entres os pressupostos se alimenta de discriminação pela "capacidade física" e na presunção de "habilidade" para o exercício de alguma atividade. Além da limitação de uso ao gênero feminino, simbolicamente a participação em esporte é entrelaçado à virilidade masculina, logo a não participação em atividades físicas emana à homens e meninos uma noção social de fraqueza, compreendendo ao meio social como um sujeito incompleto as faculdades atribuídas ao seu gênero.

Wenertz e Stigger (2006) em A Construção do Gênero no Espaço Escolar (2006) apontam que em determinadas situações podem ser atravessados no contexto gênero e prática esportiva significados que recaem ao indivíduo, marcando os corpos e os delimitando sobre o que podem e não podem fazer. No estudo citado os autores trabalham sobre a expressão de "cultura escolar", que compreende o misto de simbologias e ações que vem a ser reproduzidas no espaço escolar pelos diferentes sujeitos, incluindo o corpo técnico.

Tal percepção cultural exprime-se ao espaço delimitações da conduta social, que entre elas Wenertz e Stigger (2006) dialogam com situações sobre a prática do futebol no recreio escolar, apontando para o entendimento que rechaça os alunos que não tem afinidade com a modalidade, processando-o a eles uma noção de menos masculino que os praticantes. Por outro lado, foi aprendido que as meninas que praticam a modalidade futebol acabam deslegitimadas pelos alunos em geral, ao não considerarem o exercício vinculante ao gênero feminino.

A existência do conflito evidência que o espaço da quadra promulga delimitações que são impostas ao seu uso, principalmente quando os alunos do gênero masculinos querem exercer suas práticas esportivas. O que acaba mostrando que a dominação da maior parte do recorte estudado é reconhecida pela comunidade como um território que os alunos do gênero masculino influenciam e oprimem quem nele resiste. Como o fato averiguado durante a presença no ambiente escolar, onde a predominância da prática do futebol de salão era protagonista, enquanto em paralelo o vôlei e a queimada eram as práticas secundárias exercidas pelas meninas na parte periférica da quadra.

Nesse contexto, reafirma-se o que Wenetz e Stigger (2006) apontam sobre o fato de produções sociais não oficiais em espaços recreativos, que se expressam por diferentes formas e estratégias, compreendendo em significados culturais que permeiam as noções do masculino e feminino no cotidiano da escola. Significados estes que fazem parte do globo presente na constituição e manutenção dos territórios, especialmente quando se usa o território na visão imaterial e simbológica como parte da manutenção da dimensão funcional do mesmo, na linha de Haesbaert (2007). Daí a importância de que a partir dos estudos geográficos de gênero, busque-se identificar as diversas configurações dentro da organização espacial escolar.

Em outras palavras, as associações de atividades físicas e recreativas no espaço da quadra escolar evidenciam grande carga simbólica em ações que diferem o uso dos pontos pela diferença de gênero, cominando deste modo na restrição ao espaço. O que expede o entendimento da constituição de territórios em torno da apropriação, dominação e relações de poder remetidas a eles, resultando desta forma em noções atribuídas ao masculino e feminino na escola.

\section{CONSIDERAÇÕES FINAIS}

O estudo sobre a organização do espaço geográfico que envolve a perspectiva do gênero nos levou a refletir sobre as relações de dominação e propagação de significados, que por vezes estipulam e delimitam o modo de uso dos espaços escolares pelos estudantes, configurando certas formas de territórios que que reforçam o status dominante que é as ralações patriarcais.

Verificamos a partir do estudo de caso, que embora a temática de gênero esteja presente no currículo escolar, prática é pouco discutido, visto relatos dos estudantes de que pouco ouiram/falaram sobre a questão na escola. Ressalta-se que embora não seja uma questão problematiza com frequência na no ambiente escolar, uma parte dos estudantes possuem informações sobre o tema. Contudo esse esclarecimento não é suficiente para mudar o comportamento machistas e que constrangem as estudantes mulheres. Perante a dinâmica espacial observada compreende-se que há a constituição de territórios hostis as estudantes mulheres 
no espaço escolar pesquisado.

Posto isto, retifica-se a necessidade de se discutir a da temática na geografia fazendo desse, também um campo da preocupações geográficas, e na busca de contribuir em uma construção tanto prática quanto teórica de uma educação que ajude a libertar o indivíduo de armaras sociais que diferenciem sujeitos ou ainda que desconsiderem como ator do ser e fazer científico.

\section{REFERÊNCIAS}

BIROLI, Flavia. Gênero e Desigualdade: os limites da democracia no Brasil. 1 ed. São Paulo: Boitempo, 2018.

BRASIL. Secretaria de Educação Fundamental: parâmetros curriculares nacionais: terceiro e quarto ciclos: apresentação dos temas transversais / Secretaria de Educação Fundamental. Brasília: MEC/SEF, 1998.

CLAVAL, Paul. A Geografia Cultural. 3 ed. Florianópolis: UFSC, 2007.

GÊNERO e diversidade na escola: formação de professoras/es em Gênero, orientação Sexual e Relações Étnico-Raciais. Livro de conteúdo. versão 2009. - Rio de Janeiro: CEPESC; Brasília: SPM, 2009.

HAESBAERT, Rogério. Territórios Alternativos. 2․ Ed. São Paulo: Contexto, 2006.

2007.

Território e multiterritorialidade: um debate. Geographia, Niterói, UFF, ano 9, n. 17, 19-46,

LOURO, Guacira Lopes. Gênero, sexualidade e educação: uma perspectiva pósestruturalista. Petrópolis, RJ: Vozes, 1997.

SAQUET, M. A. Abordagens e concepções de território. São Paulo: Expressão Popular, 2007.

SARDINHA, M. L. N. Geografia e educação infantil: os croquis de localização - um estudo de caso. 2007. 188 f. Tese (doutorado em geografia) - USP, São Paulo, 2007.

SILVA, J. M. Algumas reflexões sobre a lógica eurocêntrica da ciência geográfica e sua subversão com a emergência de saberes não hegemônicos. Geo UERJ - Ano 11, v.2, n.19, $1^{\circ}$ semestre de 2009. p.1-16.

SILVA, J. M, et. al. O corpo como elemento das geografias feministas e queer: um desafio para a análise no Brasil. In: Geografia Malditas: corpos, sexualidades e espaços. Ponta Grossa: Todapalavra, 2013. p. 85-114.

SOUZA, Marcelo L. de. Os conceitos fundamentais da pesquisa socio-espacial. Rio de Janeiro: Bertrand Brasil, 2013.

O território: sobre espaço e poder, autonomia e desenvolvimento. In:

Geografia: conceitos

e temas. Rio de Janeiro: Bertrand Brasil, 1995.

SCOTT, Joan Wallach. Gênero: uma categoria útil de análise histórica. Educação \& Realidade. Porto Alegre, vol. 20, n 2, jul./dez. 1995, p. 71-99.

TURRA NETO, Nécio. Vivendo entre jovens: a observação participante como metodologia de pesquisa de campo. Terr@ Plural/ Dossiê Temático - Microterritorialidades Urbanas. Ponta Grossa-PR. v. 6 n., 2012.

WENETZ, I; STIGGER, M. P. A Construção do Gênero no Espaço Escolar. Movimento. Porto Alegre, v. 12, n. 01. P. 59-80. Jan, 2006. 